Dear Author,

Please, note that changes made to the HTML content will be added to the article before publication, but are not reflected in this PDF.

Note also that this file should not be used for submitting corrections. 
Research article

\title{
Assessment of groundwater vulnerability to nitrates from agricultural e4 sources using a GIS-compatible logic multicriteria model
}

\author{
Q3 Boris Rebolledo ${ }^{\mathrm{a},{ }^{*}}$, Antonia Gil a ${ }^{\mathrm{a}}$, Xavier Flotats ${ }^{\mathrm{b}}$, José Ángel Sánchez \\ a Center of Research for Energy Resources and Consumption (CIRCE), C/Mariano Esquillor Gómez 15, 50018, Zaragoza, Spain \\ b GIRO Joint Research Unit IRTA-UPC, Department of Agrifood Engineering and Biotechnology, Universitat Politècnica de Catalunya, BarcelonaTECH, Parc \\ Mediterrani de la Tecnología, Building D4, E-08860, Castelldefels, Barcelona, Spain \\ ${ }^{\mathrm{c}}$ Departamento de Ciencias de la Tierra, Área de Geodinámica, Edificio de Geológicas Pedro Cerbuna, 12, 50009, Zaragoza, Spain
}

\section{A R T I C L E I N F O}

\section{Article history:}

Received 5 October 2015

Received in revised form

26 January 2016

Accepted 30 January 2016

Available online $\mathrm{xxx}$

\section{Keywords:}

Groundwater vulnerability

Risk mapping

Nitrate pollution

Logic Scoring of Preferences (LSP)

Aragon (Spain)

\begin{abstract}
A B S T R A C T
In the present study an overlay method to assess groundwater vulnerability is proposed. This new method based on multicriteria decision analysis (MCDA) was developed and validated using an appropriate case study in Aragon area (NE Spain). The Vulnerability Index to Nitrates from Agricultural Sources (VINAS) incorporates a novel Logic Scoring of Preferences (LSP) approach, and it has been developed using public geographic information from the European Union. VINAS-LSP identifies areas with five categories of vulnerability, taking into account the hydrogeological and environmental characteristics of the territory as a whole. The resulting LSP map is a regional screening tool that can provide guidance on the potential risk of nitrate pollution, as well as highlight areas where specific research and farming planning policies are required.
\end{abstract}

(c) 2016 Published by Elsevier Ltd.

\section{Introduction}

The increasing international concern about nutrient overload into the environment has resulted in the introduction of strict regulations for the protection of water resources. Within this context, groundwater contamination by nitrates $\left(\mathrm{NO}_{3}^{-}\right)$from agricultural sources is one of the most widespread threats worldwide (Addiscott and Benjamin, 2004; Karr et al., 2001; Weyer et al., 2001). Due to this threat the EU drew up the Nitrate Directive 91/ $676 /$ EC concerning the protection of waters against nitrate from agricultural sources.

Since the EU Nitrate Directive was adopted, important differences have been observed in the methods and approaches used to identify Nitrate Vulnerable Zones (NVZs) (European Commission, 2013). Although criteria for identifying the NVZs were established in the Nitrate Directive, the specific procedure for the delimitation of these vulnerable areas is still unclear. Furthermore, recent research has shown that an inadequate designation of NVZs can generate unsatisfactory results in the contamination reduction of affected water bodies (Arauzo and Martínez-Bastida, 2015; Arauzo

\footnotetext{
* Corresponding author.

E-mail address: brebolle@unizar.es (B. Rebolledo).
}

and Valladolid, 2013; Worrall et al., 2009).

In Spain, the regional administrations are responsible for identifying NVZs from agricultural practices. In general, analysis of water quality data from networks of monitoring stations has been used to designate vulnerable zones, and administrative boundaries and groundwater bodies have been used to delineate the shape of these areas. Furthermore, the emphasis on the evidence of environmental damage, rather than on a proactive planning, can hinder successful conservation of water resources. Therefore, it is necessary to develop a more rational, rigorous and systematic approach.

Until now, several methods for groundwater vulnerability and risk mapping have been proposed. They range from complex deterministic models of the physical, biological and chemical nitrate leaching processes occurring in vadose zone and saturated zone (De Paz and Ramos, 2004; Lasserre et al., 1999; Ledoux et al., 2007; Srinivasan and Arnold, 1994), to methods that are based on overlay and index techniques to obtain a final vulnerability score. Index methods are based on combining rated maps of various physiographic factors (e.g., depth to water table, aquifer type, soil organic carbon content) of the region by assigning a subjective numerical score to each factor. Models of index methods include DRASTIC (Aller et al., 1987); GOD (Foster, 1987); AVI (Van Stempvoort et al., 1993); EPIK (Doerfliger et al., 1999); SINTACS 
(Civita, 1994); ISIS (Civita and De Regibus, 1995); SI (Ribeiro, 2000) and IPNOA (Padovani and Trevisan, 2002).

The traditional GIS-based multicriteria decision analysis (GISMCDA) approaches, i.e. the Boolean overlay and the weighted linear combination (WLC) have two fundamental problems with their use and interpretation. The first is related to the standardization of factors, where the common approach is to rescale the original criteria into comparable units by simple linear transformation, although in some cases a non-linear standardization would be more appropriate. The second problem stems from the logics aggregation. WLC approach is based on a "permissive" procedure of aggregation that allows a full trade-off among factors, given that in actual situations this compensation would only take place to a certain extent, while the Boolean overlay approach uses a Boolean AND or a Boolean OR to obtain a strict outcome with no trade-off (Drobne and Lisec, 2009; Eastman, 1999).

Real decision-making about "vulnerability," however, is shaped by a variety of conditions, including not only simultaneity and replaceability, but also mandatory, desired and sufficient requirements. The Logic Scoring of Preferences (LSP) method (Dujmović, 1996), unlike traditional MCDA approaches, expresses flexible logic conditions observed in the nature of environmental factors (Dujmović and Scheer, 2010; Dujmović and Tré, 2011; Dujmović et al., 2010, 2008). Consequently, it is realistic to expect that the inherent flexibility of the LSP approach can provide highly accurate and justifiable models for GIS applications (Dujmović and Scheer, 2010; Dujmović et al., 2009).

The aim of this work is to develop a territory-wide approach to assess groundwater vulnerability with the use of GIS in order to combine spatial information on hydrogeological characteristics, the natural attenuation (denitrification capacity of soil) and the effect of topography and climate (infiltration potential). Since the ultimate objective of NVZs designation is to prevent nitrate contamination from agricultural sources, the agricultural nitrogen loads are included in the risk assessment. In order to consider the complex relation between these different environmental and hydrogeological factors, and to overcome the weaknesses of traditional MCDA approaches, LSP was selected as aggregation technique. To facilitate the understanding of the study, Vulnerability Index to Nitrates from Agricultural Sources (VINAS-LSP) was applied to a case study in Aragon (Northeast of Spain).

\section{Study area and problem definition}

The geographic region of Aragon, situated in NE of Spain, covers an area of $47.719 \mathrm{~km}^{2}$. Aragon can be divided into three distinct areas from north to south; the central Pyrenees in the north, the Ebro depression in the centre and, the Iberian system mountain in the south (Fig. 1).

The Ebro River system is one of the most significant river basins in the Iberian Peninsula. The region has a Continental Mediterranean climate, with warm summers and cold winters. The mean annual temperature varies between $6{ }^{\circ} \mathrm{C}$ (in the colder regions of Pyrenees) and $15^{\circ} \mathrm{C}$ (in central zones). The precipitation levels vary along the territory. The mountainous regions present the higher mean precipitation levels (between 800 and $1200 \mathrm{~mm} \mathrm{yr}^{-1}$ ), while the central zones present lower rainfall levels (between 300 and $400 \mathrm{~mm} \mathrm{yr}^{-1}$ ) (DGA, 2007).

According to the report from the Commission to the council and the European Parliament on the implementation of Council Directive 91/676/EEC, in Aragon, all groundwater bodies are affected or at risk of being so by nitrates from agricultural sources (European Commission, 2013). In 2010, nitrate concentrations in groundwater exceeded the "Maximum Acceptable Level" (MAV) equal to $50 \mathrm{mg} \mathrm{NO}-\mathrm{L}^{-1}$ at $20 \%$ of monitored sites of Aragon. Moreover, quality at $57 \%$ of groundwater monitoring points was above $15 \mathrm{mg}$ $\mathrm{NO}_{3}^{-} \mathrm{L}^{-1}$, suggesting that these control points could be subjected to nitrogen inputs from human activities (Hinsby et al., 2008; Panno et al., 2006).

The designation of NVZs implies that in these areas, farmers are required to comply with the measures laid out by local/regional water quality protection and restoration programs. It is therefore reasonable, from a methodological point of view, to propose a new method for the designation of these NVZs based on hydrogeological and environmental factors, instead of on administrative boundaries (municipal, provincial, etc.), which is the case of Spain.

\section{Development of the spatial multicriteria model}

The different GIS-MCDA approaches differ significantly in the details of how values are assigned and combined, but the common purpose of these diverse methods is to provide a specific criterion function for computing an overall degree of suitability (Dujmović et al., 2009). In this study, the criterion function describes the relationship between inputs (environmental and hydrological factors) and a complex output related to vulnerability, where each cell value should indicate the continuous degree of membership [0,1] that elementary criteria as a whole have within a fuzzy "vulnerability" class. This calls for a framework to integrate factual information on groundwater vulnerability with rational and structured preferences of decision-makers.

Fig. 2 shows a high-level view of major steps followed in this study. First, the problem and the purpose of the study must be clearly defined. The next step is the selection of elementary criteria (factors) that will be used in the evaluation. In this point, the statistical independence between the set of selected factors is verified by Pearson's correlation coefficient technique. Afterwards, the standardization process is carried out by transforming the different measurement units of the raster datasets (e.g. soil organic carbon content, $\mathrm{pH}$, terrain slope, mean rainfall, etc.) into a comparable range $[0,1]$ using fuzzy membership functions. In the next point, a preliminary LSP-system factor tree is established for decomposing the complex decision problem. Then, a pairwise comparison questionnaire was made for eliciting expert opinions. Consequently, Analytical Hierarchy Process (AHP) (Saaty, 1980) was selected to obtain the factor weights (relative importance). After that, the next step involves selecting an appropriate LSP aggregation structure to combine the elementary criteria (factors). At the end of the study, a Global Sensitivity Analysis (GSA) was carried out to quantify the output uncertainty due to the uncertainty in the elementary criteria. Finally, a statistical technique was used to test the validity of the spatial multicriteria model output.

\subsection{Selection of elementary criteria (factors)}

In a regional planning context, groundwater vulnerability depends on the degree of aquifer vulnerability to $\mathrm{NO}_{3}^{-}$leaching (intrinsic vulnerability) as well as on a range of environmental factors involved both in the natural attenuation and water infiltration processes.

The inclusion of factors used here is based mainly on an extensive literature review and the judgment of the authors and environmental consultants. In order to perform the study, eleven factors were selected and clearly classified into four main groups according to their participation in the main processes involved in the evaluation. A brief description of VINAS-LSP factors is shown in Table 1 and described below.

The first group comprises factors related to intrinsic vulnerability (hydrogeological factors, $\mathrm{HF}$ ), i.e. aquifer type $\left(\mathrm{HF}_{\mathrm{AT}}\right)$, permeability of vadose zone ( $\left.\mathrm{HF}_{\mathrm{PV}}\right)$ and water table depth ( $\left.\mathrm{HF}_{\mathrm{WD}}\right)$. 


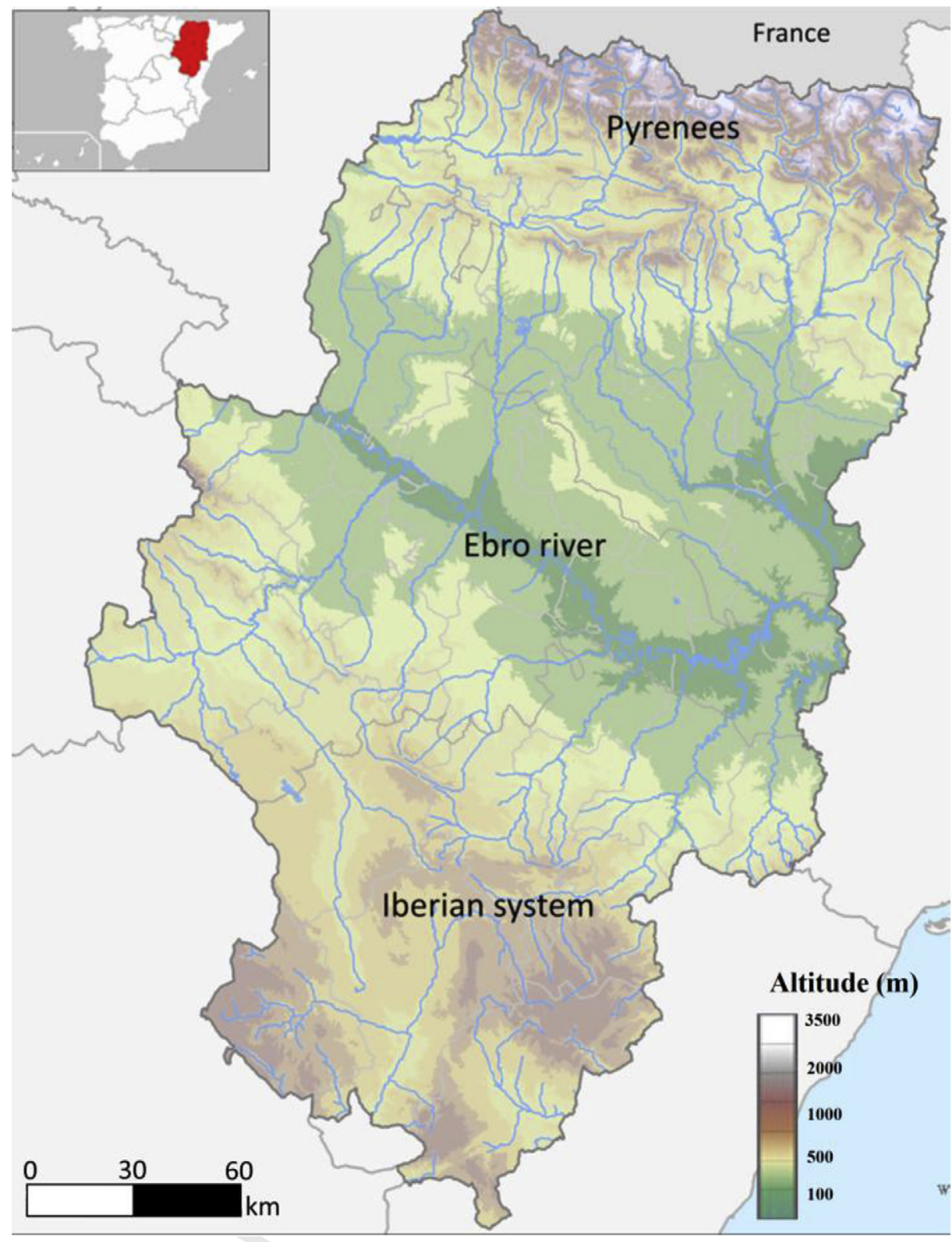

Fig. 1. Location map of Aragon (DGA, 2012).

The second group includes factors affecting denitrification in soil (attenuation factors, $\mathrm{AF})$, i.e. topsoil texture $\left(\mathrm{AF}_{\mathrm{TT}}\right)$, organic carbon $\left(\mathrm{AF}_{\mathrm{OC}}\right)$ and $\mathrm{pH}\left(\mathrm{AF}_{\mathrm{pH}}\right)$. The third group comprises two complementary subgroups (climate and relief) related to infiltration potential (infiltration factors, $I F$ ), i.e. rainfalls level $\left(I_{R L}\right)$, evapotranspiration $\left(\mathrm{IF}_{\mathrm{ET}}\right)$, slope percent $\left(\mathrm{IF}_{\mathrm{SP}}\right)$ and flow accumulation $\left(\mathrm{IF}_{\mathrm{FA}}\right)$. The combination of these three groups of layers using a logical structure and an adequate aggregation procedure, allows assessing the vulnerability of an area to nitrate pollution. However, it is necessary to add a fourth group of factors (nitrogen factors, NF) for risk mapping purposes. This is because risk of pollution is determined not only by the above groups of factors, which are relatively static, but also on the existence of potentially polluting activities, which are dynamic factors that can, to a certain extent, be modified and controlled. In this case study, only $\mathrm{N}$ loads from agricultural non-point sources were considered $\left(\mathrm{NF}_{\mathrm{LC}}\right)$.

Once the criteria factors of VINAS-LSP were selected, the second stage in this step was to construct a spatial database covering
Aragón. In order to avoid the double counting of their effects, the statistical independence was successfully verified by Pearson's correlation coefficient technique through GIS tools.

All the geographic information used for developing the VINASLSP model has been obtained from Spanish Government websites or EU public data sources (Table 1). For the application of VINAS-LSP across Spain, all the GIS information (raster datasets) can be obtained from local Spanish agencies and EU websites.

\subsection{Fuzzy factor standardization}

In order to prepare the criteria factors for spatial data overlay computation, all of them were converted with the same output grid cell size (200-m), and then they were defined as raster maps of standardized values, transforming the different measurement units of the raster maps into a continuous comparable range $[0,1]$. Zero value was assigned to the lower degree of vulnerability class membership (least vulnerable), and 1 to the most vulnerable (full 


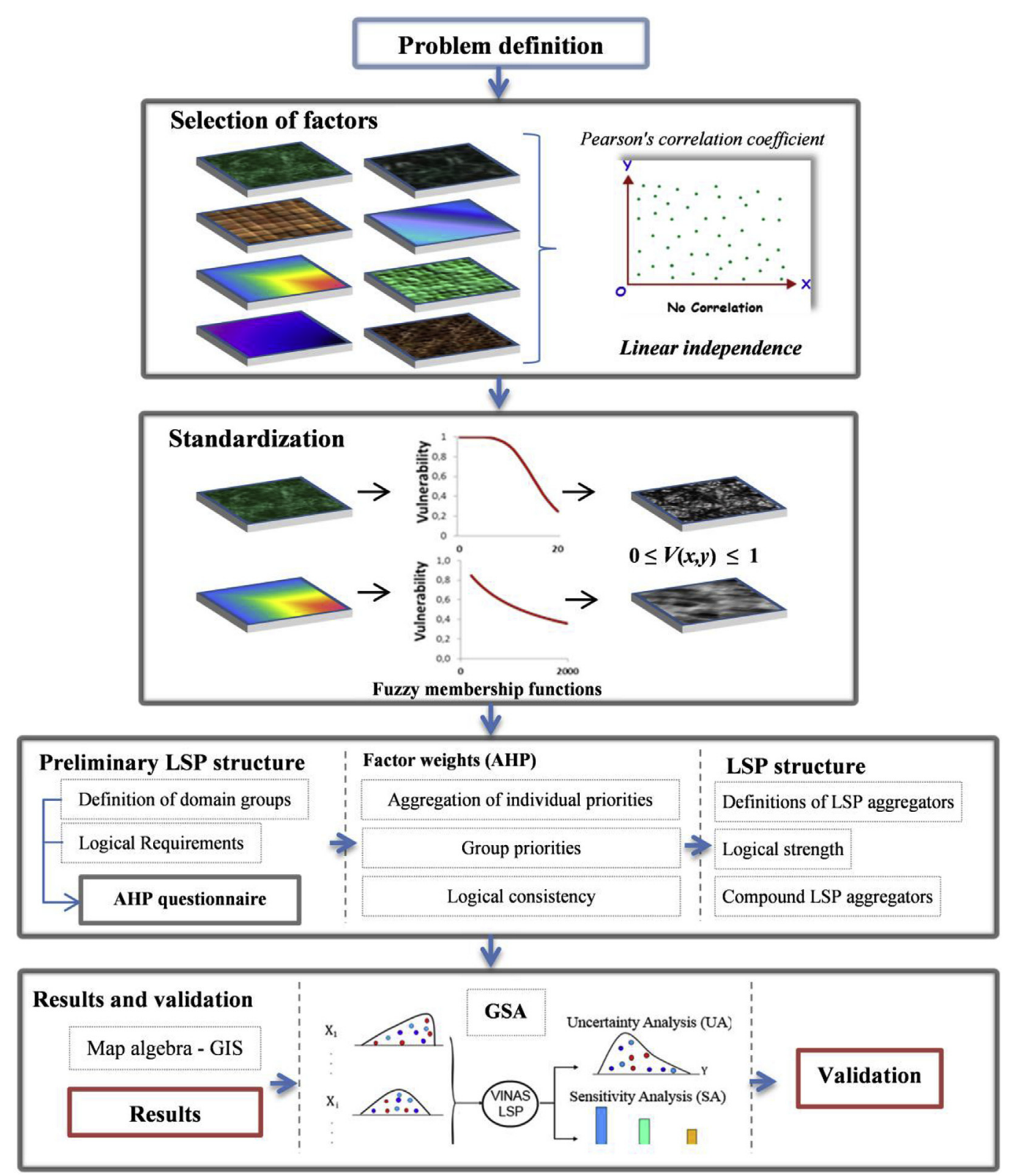

Fig. 2. Schematic representation of the methodology.

membership in the fuzzy set). The standardization process was executed using the Spatial Analyst Module of ArcGis software. In this process, fuzzy membership functions (discrete and continuous functions) specified for each factor were used. The selection of fuzzy membership functions and the criterion's preferences to apply to each factor were based on the expertise of the authors. Meanwhile, the selection of parameters that define the shape of fuzzy membership functions (spread, midpoint and threshold of preferences), and characterize the association strength between a raster input value and a degree of membership in a set, was based on an extensive literature review. For instance, a value of $6.73 \%$ (soil organic carbon content) was selected for assigning the lowest degree of vulnerability according to the highest value found by Ryden and Whitchead (1988). IFRL and IFET were standardized according to the average annual rainfall $(548 \mathrm{~mm} / \mathrm{year}$ ) and potential evapotranspiration (1114 mm/year) of Aragon. In the case of NFLC, the threshold of $174(\mathrm{Kg} \mathrm{N} / \mathrm{ha} \cdot$ year) is the average nitrogen loading rate of irrigated crops in Aragon. Further details about standardization of VINAS-LSP factors can be found in Rebolledo (2014).

The fuzzy transformation functions and the standardized criteria input maps of VINAS-LSP are shown in Fig. 3 and Fig. 4, respectively. While the most factors were automatically rescaled by means of continuous fuzzy functions (small, large, near, linear), in some ordinal data such as permeability of vadose zone (HFPV) and aquifer type (HFAT), where the base maps were already classified, specific scores were assigned to each category based on expertise and knowledge, according to their relative vulnerability to nitrate pollution.

\subsection{Model development - LSP aggregation procedure}

The first task of this stage involved the construction of an attribute tree that organizes the decision problem and contains all the factors considered in the study. The attribute tree was divided 
Table 1

Description of the model input factors.

Factor Justification

GIS data and information sources

$\mathrm{HF}_{\mathrm{AT}}$ Aquifer type is the first attempt for including the hydraulic properties of confining layers

(Galve et al., 2005)

HFWD Water table depth. In general, groundwater vulnerability decreases as the depth of water table increases.

(Galve et al., 2005)

$\mathrm{HF}_{\mathrm{PV}}$ Permeability of vadose zone is a measure of water moving through the pores of a saturated soil. Thus, high permeability zones are (Galve et al., 2005) generally more susceptible to nitrate leaching.

$\mathrm{AF}_{\mathrm{TT}}$ The topsoil texture has an important role in the attenuation of nitrogen through the denitrification process.

(European Commission, 2004)

$\mathrm{AF}_{\mathrm{OC}}$ Organic Carbon. Denitrification takes places in anaerobic conditions (waterlogged soil) and where there is organic matter (organic (Jones et al., 2003) carbon) to provide energy for bacteria

$\mathrm{AF}_{\mathrm{pH}}$ Between attenuation factors, $\mathrm{pH}$ has a secondary role because its inclusion is not obligatory in the denitrification context; however it (Böhner et al., 2008) can enhance the denitrification potential of soils.

$\mathrm{IF}_{\mathrm{RL}} \quad$ Rainfall level. The infiltration of precipitation is the main process for transporting nitrate. Then, high rainfall levels can increase the SICLIMA (DGA, 2012) amount of nitrate leached from the soil by infiltrating rain.

$\mathrm{IF}_{\mathrm{ET}}$ Evapotranspiration. Any factor influencing soil moisture (such as rainfall, irrigation, evaporation and transpiration) will impact nitrate (Cuadrat et al., 2007) movement.

IF $\quad$ The topographic slope (\%) can enhance the movement of nitrate-N to surface waters (surface runoff), and on the other hand it can IDEARAGON (DGA, 2014) increase the amount of water infiltration.

IF Flow accumulation. When a certain amount of water (usually from rainfall) is accumulated on the land surface, then a thicker water IDEARAGON (DGA, 2014) film can lead to an increase on infiltration potential.

$\mathrm{NF}_{\mathrm{LC}}$ Land cover. The extent of nitrate leaching to groundwater depends on the previous factors, as well as on the nitrogen fertilizer loadings Corine Land Cover 2006 (organic and chemical loads) (CLC2006)

(Andreu et al., 2006)

into three levels - A, B and C, denoting Factors layer, Systems layer and Objective layer, respectively. Subsequently, a questionnaire was designed based on pairwise comparison according to AHP method to collect the opinion of environmental experts. The questionnaire was subjected to expert opinions to ensure that the questions were well understood and consistent with the aim of the research. A total of 10 environmental experts were involved in the eliciting of scores for selected factors. The group consisted of hydrogeologists, geographers, chemists, experts in soil science and environmental scientists.

Another key aspect in this stage was to obtain a single group priority vector $\mathrm{W}^{\mathrm{G}}$ as a joint estimate of judgments of experts. In this study, the experts group who answered the questionnaire belongs to different institutions and scientific fields, where their decisions are personal and independent. Therefore, aggregating their individual (final) priorities (AIP) was selected as aggregation method.

In regard to the exploitation phase of AIP, i.e. the process of deriving a priority vector $\mathrm{w}=\left(\mathrm{w}_{1}, \ldots, \mathrm{w}_{\mathrm{n}}\right)^{\mathrm{T}}$, where $\mathrm{w}_{\mathrm{i}} \geq 0$ and $\sum_{\mathrm{i}=1}^{\mathrm{n}} \mathrm{w}_{\mathrm{i}}=1$, the Row Geometric Mean Method (RGMM) was selected as aggregation procedure, because its use guarantees that the group inconsistency is at least as good as the worst individual inconsistency (Escobar et al., 2004).

Since the obtained priorities make sense only if derived from consistent or near consistent AHP matrices, a consistency check was applied. In the analysis of individual and group consistency, Geometric Consistency Index (GCI) was correctly verified according to the thresholds provided by Aguaron and Moreno-Jiménez (2003), where $\mathrm{GCI}=0.3147$ (for $\mathrm{n}=3$ ), $\mathrm{GCI}=0.3526$ (for $\mathrm{n}=4$ ) and $\mathrm{GCI}=0.370$ (for $\mathrm{n}>4$ ). The attributes tree, the group priorities (weights) of each factor as well as system layers are shown in Table 2.

The results from this study should be interpreted with caution, since the main focus of this study is on presenting the implementation of VINAS-LSP within MCA framework rather than discussing about the relative importance of each factor, and therefore more detailed studies can be performed for obtaining priority weights.

The last and most important step in the model development stage was the organization of the preference aggregation structure. The aim of this step is to create the VINAS-LSP system, where factors are aggregated and combined in a stepwise, non-linear way. LSP allows to model a continuous variety of logical conditions and simple LSP aggregators can be used to construct more complex, compound operators like Conjunctive Partial Absorption (CPA) to express some asymmetric logic relationship between factors (Dujmović and Scheer, 2010). This was considered a key issue for aggregation method selection, because through CPA is possible to aggregate mandatory and desired factors. For instance, in VINASLSP system, the $\mathrm{pH}$ factor is considered as "desired" but not mandatory within the denitrification potential context.

The final aggregation structure of VINAS-LSP is shown in Fig. 5, where a series of LSP aggregators were implemented using the Weighted Power Mean (WPM) to combine each factor into a final score of suitability $(S)$, as can be seen in the Eq. (1) (Dujmović et al., 2009)

$$
\begin{aligned}
& S=\left(\sum_{i=1}^{n} w_{i} x_{i}^{r}\right)^{1 / r}, 0<w_{i}<1, \quad 0 \leq x_{i} \leq 1, \quad i=1, \ldots n \\
& \sum_{i=1}^{n} w_{i}=1, \quad-\infty \leq r \leq \infty, \quad 0 \leq S \leq 1
\end{aligned}
$$

where $x_{i}$ represents an input factor, $w_{i}$ denotes the factor weight reflecting the relative importance of the selected input, and $r$ is the parameter that determines the logical behavior of the function and it expresses the strength of association between mandatory and optional factors.

Fig. 5 shows the sequential computation of the potential risk to nitrate pollution for each pixel of the study area, used in the VINASLSP system. Four simple LSP aggregators were selected $\left(\mathrm{C}^{-}, \mathrm{CA}, \mathrm{A}\right.$ and DA), where their parameter $r$ values are as follows: 0.261 ( $C^{-}$or soft partial conjunction), -0.72 (CA or hard partial conjunction), 1 (A or neutrality) and 3.929 (DA or partial disjunction), following Dujmović and Nagashima (2006). The values of input arrows denote the factors weights, whose values were recalculated from the original weights (Table 2) while proportionality was kept constant. In the CPA aggregators, if a mandatory input factor is partially (or completely) satisfied and the desired input is not satisfied, then the aggregation score will be reduced by a certain percentage (Penalty, P). On the other hand, if a mandatory input factor is partially satisfied and a desired factor is completely 

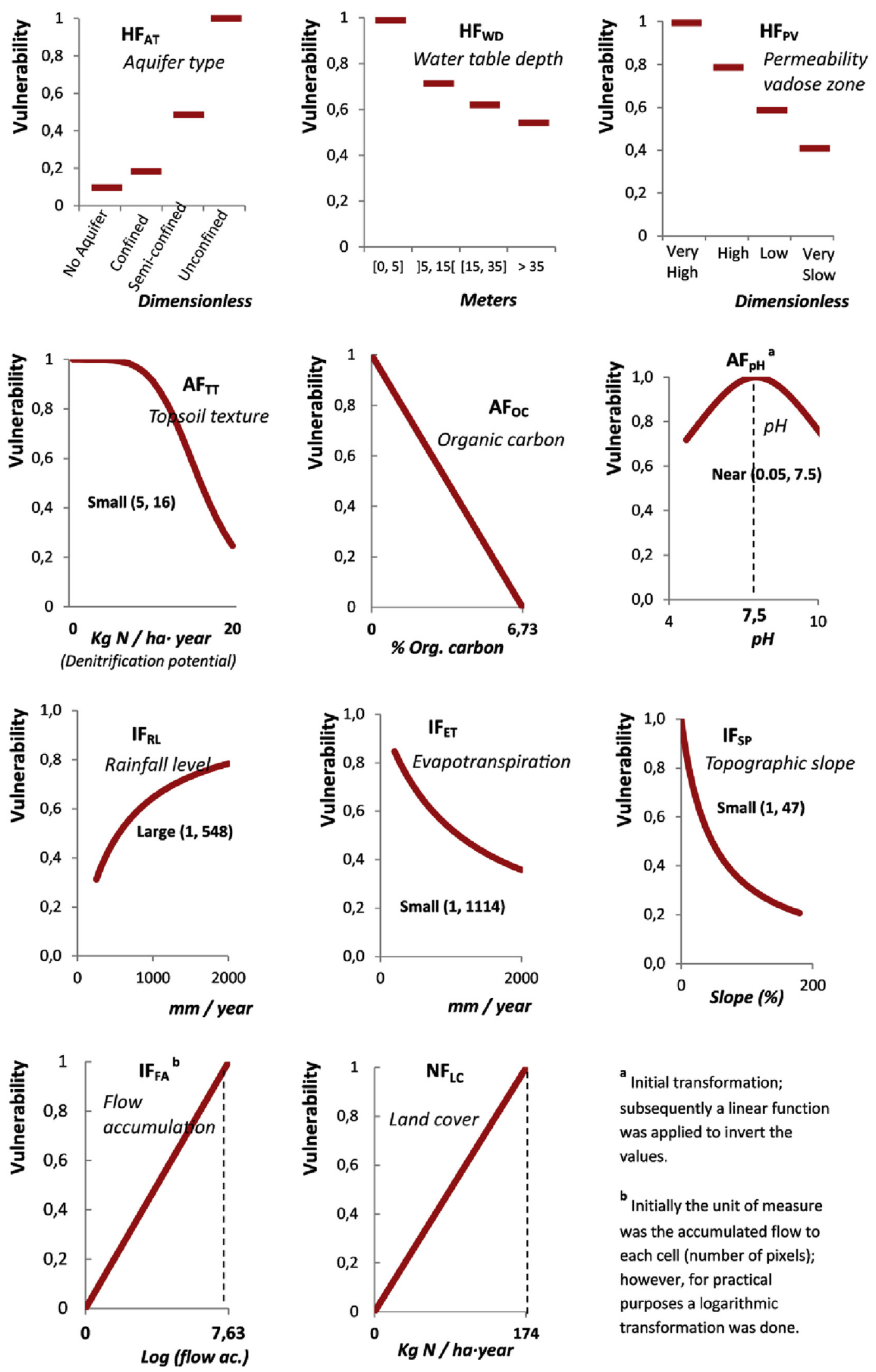

Fig. 3. Fuzzy membership functions used in the standardization process. 

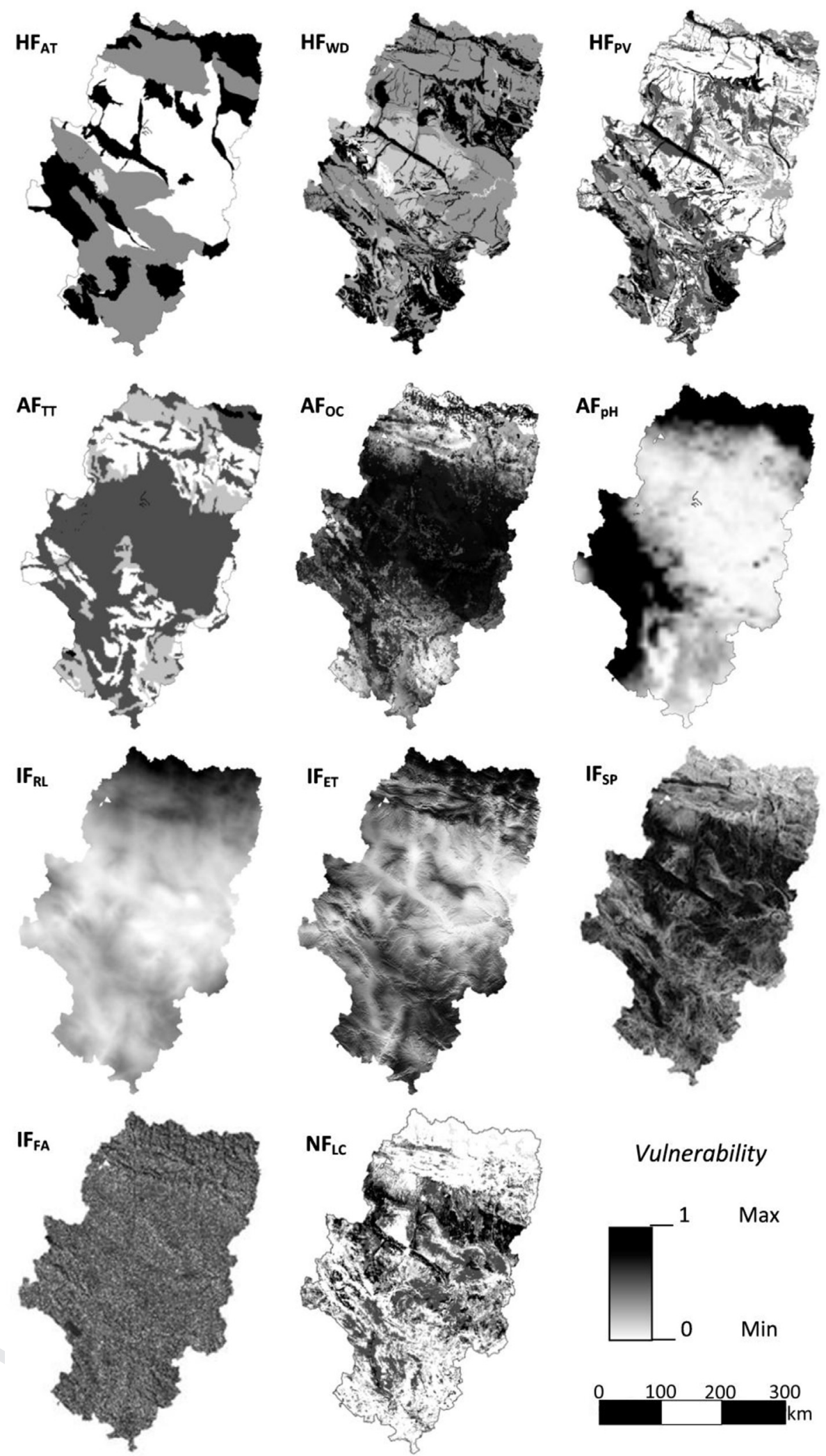

\section{Vulnerability}
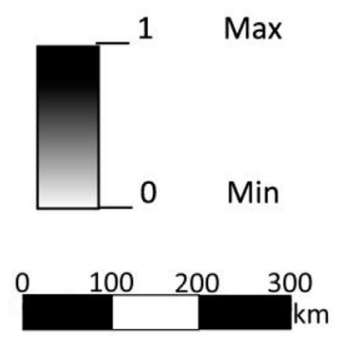

Fig. 4. Standardized criteria input maps of VINAS-LSP.

satisfied, then the aggregation score will be increased by a proportion (Reward, R). The values for Penalty and Reward have been established according the expertise of the authors and external consultants. The weights of CPA aggregators in VINAS-LSP were obtained from specialized penalty/reward tables (Dujmovic, 1979) by selecting sound $\mathrm{P} / \mathrm{R}$ values, described below. compatible logic multicriteria model, Journal of Environmental Management (2016), http://dx.doi.org/10.1016/j.jenvman.2016.01.041 
Table 2

Weights of factors and system layers of VINAS-LSP

\begin{tabular}{lllll}
\hline A: Factors & Weight $^{\mathrm{a}}$ & B: Systems & Weight $^{\mathrm{a}}$ & C: Objective \\
\hline $\mathrm{HF}_{\mathrm{AT}}$ & 0.339 & Hydrogeological setting & 0.390 & Potential risk \\
$\mathrm{HF}$ & 0.251 & (HS) & & Nitrate pollution \\
$\mathrm{HF}$ & 0.410 & & \\
$\mathrm{AF}$ & 0.388 & Denitrification potential & 0.093 & \\
$\mathrm{AF}_{\mathrm{OC}}$ & 0.489 & $(\mathrm{DP})$ & & \\
$\mathrm{AF}_{\mathrm{pH}}$ & 0.123 & & & \\
$\mathrm{IF}_{\mathrm{RL}}$ & 0.572 & Infiltration potential & 0.144 & \\
$\mathrm{IF}_{\mathrm{ET}}$ & 0.119 & $(\mathrm{IP})$ & & \\
$\mathrm{IF}_{\mathrm{SP}}$ & 0.182 & & & \\
$\mathrm{IF}_{\mathrm{FA}}$ & 0.127 & & & \\
$\mathrm{NF}_{\mathrm{LC}}$ & 1.000 & Nitrogen sources (NS) & 0.373 & \\
\hline
\end{tabular}

a Weight values were calculated by Row Geometric Mean Method from pairwise comparison matrices according to AHP method.

The factors related to hydrogeological setting (block 1) were combined by a CPA aggregator, which is used for simultaneously modeling the asymmetrical relation among two factors considered as mandatory ( $\mathrm{HF}_{\mathrm{AT}}$ and $\mathrm{HF}_{\mathrm{PV}}$ ) and an optional factor (but not mandatory) $\mathrm{HF}_{\mathrm{DG}}$. The $\mathrm{CPA}$ aggregator was built from a neutral aggregator (A) and a hard partial conjunction aggregator (CA). In this case, the full satisfaction of the optional factor $\left(\mathrm{HF}_{\mathrm{DG}}\right)$ increases the non-zero score of the mandatory factors with a reward of $15 \%$, and a null $\mathrm{HF}_{\mathrm{DG}}$ score assigns a penalty (25\%) to the mandatory factors.

In the second block (Denitrification potential), a partial disjunction aggregator (DA) was used first to represent the replaceability between $\mathrm{AF}_{\mathrm{TT}}$ and $\mathrm{AF}_{\mathrm{OC}}$. In this sense, a good condition for the attenuation process (denitrification) is characterized by an appropriate topsoil texture or by high organic carbon content. Subsequently, a CPA aggregator was used to establish the asymmetrical relation between the previous factors (mandatories) and the $\mathrm{pH}$ optional factor (not mandatory). In this case, the penalty and reward were set in $15 \%$ and $5 \%$, respectively.

The third block related to infiltration potential is comprised of two subgroups: Climate $\left(\mathrm{IF}_{\mathrm{RL}}\right.$ and $\left.\mathrm{IF}_{\mathrm{ET}}\right)$ and Relief $\left(\mathrm{IF}_{\mathrm{SP}}\right.$ and $\left.\mathrm{IF}_{\mathrm{FA}}\right)$. These four factors were combined first by two complementary CPA

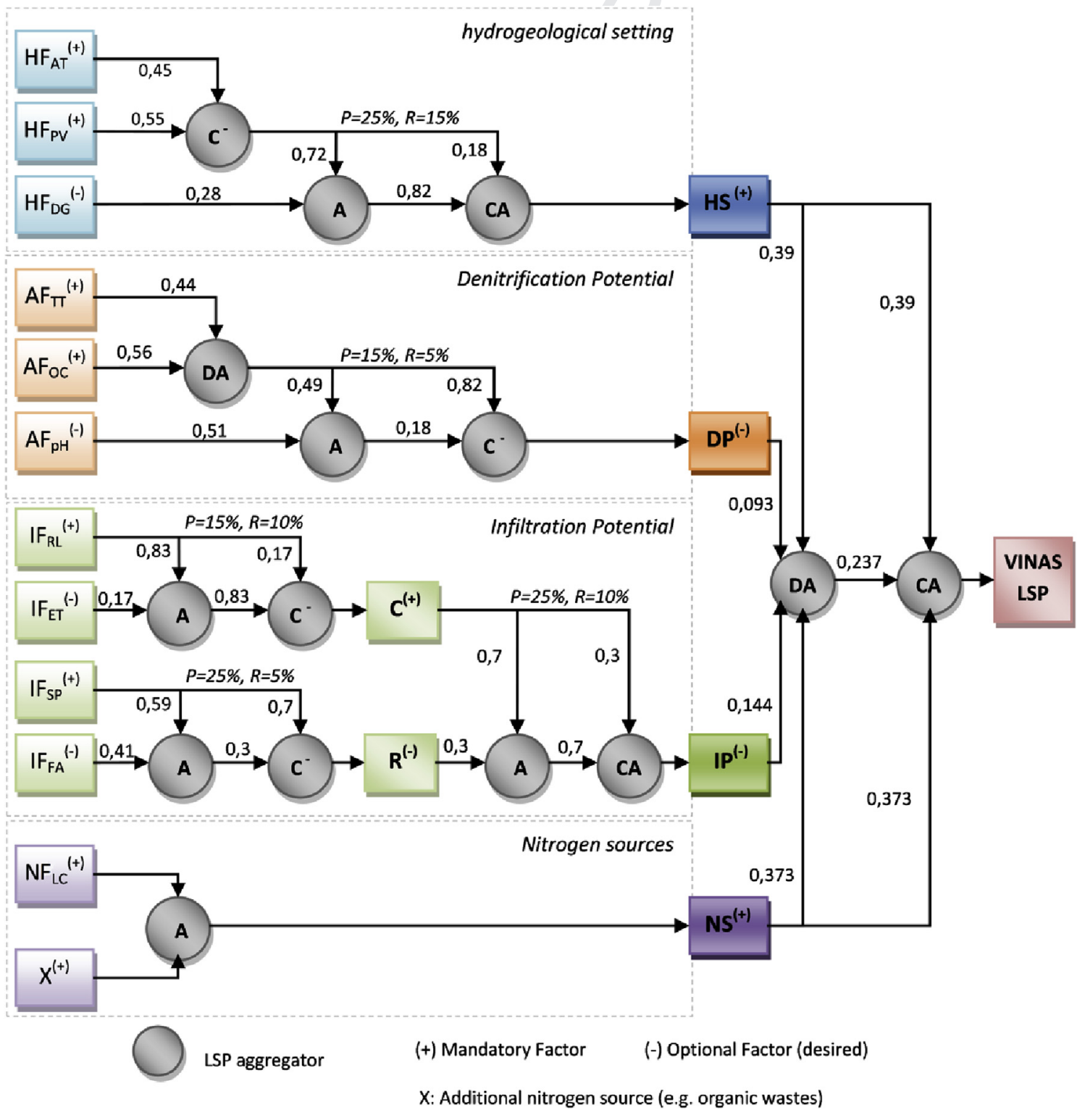

Fig. 5. VINAS-LSP aggregation structure. 
aggregators to obtain a single score within their respective domains (climate and relief), and then a CPA aggregator was built from a neutral LSP aggregator (A) and a hard partial conjunction aggregator (CA). In the infiltration potential context, the full satisfaction of the optional subgroup (relief) increases the non-zero score of mandatory subgroup (climate) with a reward of $10 \%$; otherwise a penalty of $25 \%$ is assigned.

The last block (nitrogen factors) represents the relation of neutrality (A) among different potential sources of nitrogen. In this case study, only $\mathrm{N}$ loads from agricultural non-point sources were considered (NFLC).

Finally, the blocks outputs were combined by a Continuous Preference Logic (CPL) aggregator, which was used for modeling the relation among two LSP systems considered as mandatories (hydrogeological setting and nitrogen sources) and two optional LSP systems (denitrification and infiltration potential).

Once the selected GIS operations (Map algebra) were successfully executed by means of the raster calculator of ArcGis software, the resulting VINAS-LSP map represents the potential risk to nitrate pollution from agricultural $\mathrm{N}$ loads (Fig. 6). The output map and its analysis are presented in the next section.

\section{Results and validation}

GIS-based MCDM, as well as mathematical models, are used to give a simplified abstraction of reality and, therefore, their results must be contrasted to verify its usefulness. For this reason, in this study, Global Sensitivity Analysis (GSA) was first carried out, since this made possible the simultaneous analysis of all interactions between input factors and model output results (Saltelli et al., 2000). Finally, the usefulness of the VINAS-LSP model was tested, regarding whether it adequately represents the system under study; this was carried out by means of a statistical technique to test the validity of the final LSP map, by contrasting the model output with nitrate levels of the study area.

\subsection{Sensitivity analysis (SA)}

The aim of a Sensitivity Analysis is to explore the degree of influence of input factors on the model output. While traditional oneparameter-at-a-time sensitivity analysis (OAT-SA) is based on small changes or perturbations in the initial range of the factors to assess the influence of each input factor in the variance of the model results, GSA methods (Fast, E-Fast, Sobol') consider the full ranges of uncertainty of the inputs, and allow the quantification of interactions between different input factors (Lilburne and Tarantola, 2009).

In this section, rather than attempting to validate the model itself, the focus instead is on evaluating the simultaneous importance of factors by GSA. This approach would improve the knowledge of VINAS-LSP, either to simplify the model or to focus on those most important factors.

The GSA of VINAS-LSP was based on performing multiple model evaluations with randomly selected model input factors. First, the probability density functions (PDF) of each input factor were identified. Further details about PDFs of VINAS-LSP factors can be consulted in Rebolledo (2014). Then, VINAS-LSP was run applying a Monte Carlo simulation (5000 iterations) by means of Simlab 2.2 software (JRC, 2006). The choice of the GSA method was based on the assumed relationship between the input factors and model outcome. The Extended Fourier Amplitude Sensitivity Testing (EFAST) method was applied because it allows estimating a total

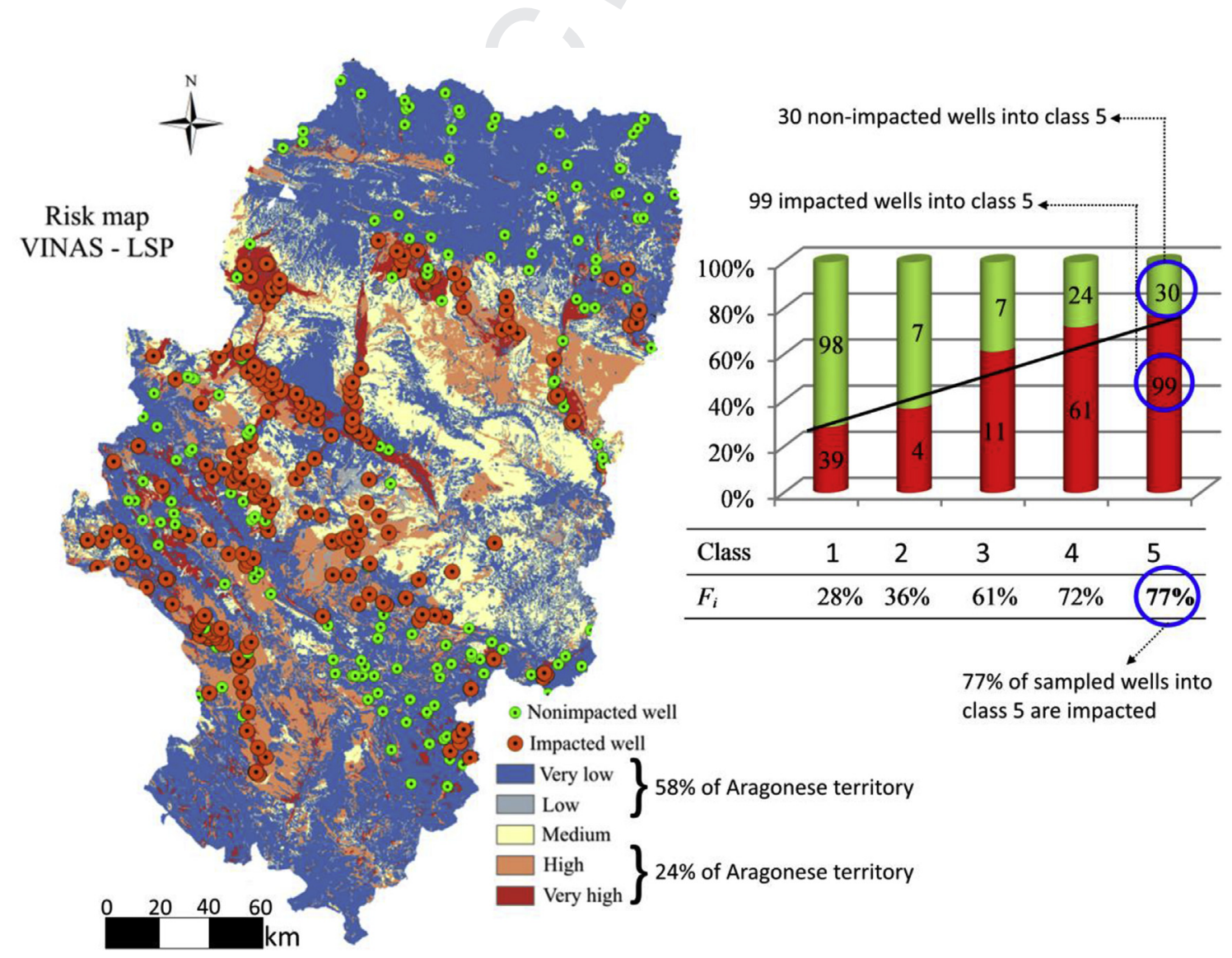

Fig. 6. Nitrate pollution risk map and validation results. 
sensitivity index $\left(\mathrm{S}_{\mathrm{T} i}\right)$, where $\mathrm{S}_{\mathrm{T} i}$ is defined as the sum of all indices ( $S_{i}$ and higher orders), thus providing a useful tool to determine factor interactions (Crosetto et al., 2000). The sensitivity indices are reported in Table 3.

The most important factors are related to nitrogen load, $\mathrm{NF}_{\mathrm{LC}}$ $\left(\mathrm{S}_{\mathrm{i}}=58.9 \%\right)$ and hydrogeological setting, $\mathrm{HF}_{\mathrm{AT}}\left(\mathrm{S}_{\mathrm{i}}=14.9 \%\right)$ and $\mathrm{HF}_{\mathrm{PV}}$ $\left(S_{i}=8.4 \%\right)$, and thus most of the output variability $(82.2 \%)$ is explained by these 3 factors. In addition, these results highlight the lowest influence played by the other 8 factors, which accounted for $17.8 \%$ of output variability as a whole. Therefore, factors like slope percent $\left(\mathrm{IF}_{\mathrm{SP}}\right)$ or flow accumulation $\left(\mathrm{IF}_{\mathrm{FA}}\right)$ could be removed from the model due to their relatively low importance in the case that the base information is not available.

In a second analysis, i.e. considering the interactions among factors, it is noticeable the reduction of $\mathrm{S}_{\mathrm{T} i}$ values of the most individually important factors $\left(S_{i}\right)$. Consequently, the more insignificant factors $\left(\mathrm{IF}_{\mathrm{SP}}, \mathrm{IF}_{\mathrm{FA}}\right)$ increase their importance by considering the interactions of VINAS-LSP. Another interesting result is the increases of the importance of $\mathrm{IF}_{\mathrm{SP}}$, increasing its rank value, from eleventh to seventh place. In light of these results and since the 8 least important factors are responsible for a significant fraction of output variability (31.3\%) their inclusion in VINAS-LSP is fully justified.

\subsection{Validation}

To determine the usefulness of VINAS-LSP as a method for groundwater vulnerability and risk mapping a statistical technique was applied. This approach was successfully used by Chowdhury et al. (2003) and Masetti et al. (2007) in research related to groundwater quality.

The strategy was based on two well populations (impacted and non-impacted wells), extracted from the Aragon groundwater quality network, including more than 380 stations (year 2010). Wells with a nitrate concentration $\geq 15 \mathrm{mg} \mathrm{NO}_{3}^{-} \mathrm{L}^{-1}$ were set as "nitrate-impacted wells," and wells with a nitrate concentration $<15 \mathrm{mg} \mathrm{NO}_{3}^{-} \mathrm{L}^{-1}$ were set as "non-impacted wells". Simultaneously, from VINAS-LSP output map, five equal interval classes of risk were considered (from very high risk to very low risk). Subsequently, using GIS to extract the risk class from the base map with respect to each well location, a proper association between both well populations and risk classes of VINAS-LSP output map was determined. Histograms were obtained considering the frequency of occurrence of non-impacted and impacted wells within each risk class, given by

$F_{i}=\frac{X I_{i}}{X I_{i}+X N I_{i}} * 100 \quad i=1,2, \ldots, 5$

where $X I_{i}$ is the number of impacted wells in the risk class " $i$ " and

Table 3

Results of the Global sensitivity analysis (GSA) with E-FAST $(\mathbf{n}=5000)$.

\begin{tabular}{lcclc}
\hline Factor & Normalized $\mathrm{S}_{\mathrm{i}}(\%)$ & Ranking $\mathrm{S}_{\mathrm{i}}$ & Normalized $\mathrm{ST}_{\mathrm{i}}(\%)$ & Ranking $\mathrm{S}_{\mathrm{Ti}}$ \\
\hline $\mathrm{NF}_{\mathrm{LC}}$ & $58.9 \%$ & 1 & $49.5 \%$ & 1 \\
$\mathrm{HF}$ & 2 & $12.5 \%$ & 2 \\
$\mathrm{HF}$ & $14.9 \%$ & 3 & $6.7 \%$ & 3 \\
$\mathrm{IF}_{\mathrm{RL}}$ & $8.4 \%$ & 4 & $6.3 \%$ & 4 \\
$\mathrm{HF}$ & $7.2 \%$ & 5 & $5.5 \%$ & 5 \\
$\mathrm{AF}$ & $6.9 \%$ & 6 & $3.5 \%$ & 8 \\
$\mathrm{AF}_{\mathrm{TT}}$ & $1.0 \%$ & 7 & $2.1 \%$ & 11 \\
$\mathrm{AF}_{\mathrm{OC}}$ & $0.7 \%$ & 8 & $3.3 \%$ & 9 \\
$\mathrm{IF}_{\mathrm{ET}}$ & $0.6 \%$ & 9 & $3.0 \%$ & 10 \\
$\mathrm{IF}_{\mathrm{FA}}$ & $0.5 \%$ & 10 & $4.0 \%$ & 6 \\
$\mathrm{IF}_{\mathrm{SP}}$ & $0.4 \%$ & 11 & $3.6 \%$ & 7 \\
\hline
\end{tabular}

$X N I_{i}$ is the number of non-impacted wells in the same risk class $i$. Thus, the $F_{i}$ parameter allows evaluating the usefulness of the VINAS-LSP model for risk mapping purposes, since it is reasonable to expect that as $i$ value increases ( $1=$ very low risk and $5=$ very high risk) the $F_{i}$ value also increases.

The distribution of the calculated risk classes within the given study area, according to the 5 different levels of potential risk, is shown in Table 4. Based on the VINAS-LSP score obtained, around $58 \%$ of the Aragonese territory falls into the very low and low classes, $24 \%$ into high and very high classes, and the remaining $18 \%$ in the medium class.

The final output map obtained by VINAS-LSP model, in reference to the study area, is shown in Fig. 6. The raster has a spatial resolution of $200 \times 200 \mathrm{~m}$. Additionally, the results of the validation process are also shown. The choice of cell size is based on the best resolution of raster datasets of Aragon and the size of the study area (regional scale).

Results of the validation procedure show that increasing the risk class also increases the $F_{\mathrm{i}}$ values. In territories qualified as high (class 4 ) and very high (5) risk, $72 \%$ and $77 \%$ of sampled wells are impacted, respectively. VINAS-LSP has therefore proved to be a valuable tool for risk mapping purposes. The validity period of this cartography depends greatly on the changes of agricultural land uses. Therefore, if there is any evidence of significant changes related to nitrogen loads, the results from this study should be interpreted with caution.

\section{Conclusions}

The presented VINAS-LSP model provides a useful tool to tackle the problem of lack of a methodology for the study of NVZs in Spain, also providing a comprehensive method for the construction of potential risk map to nitrate pollution, based on hydrogeological and environmental factors, instead of on administrative boundaries or other nonscientific criteria. Since the saltwater intrusion occurs naturally to some degree in most coastal aquifers and it affects the groundwater quality, the VINAS LSP model should not be applied directly to Spanish coastal areas, without due regard to relevant considerations.

The general structure of the model may be applied to other European regions where the base information is available, taking into account the local legislation and recalculating the weights of the factors according to their priorities. Additionally, a different approach may be adopted when considering the agricultural $\mathrm{N}$ loads (i.e. binary variable, $1=$ agricultural land and $0=$ non agricultural land) for the purposes of designation of NVZs.

The overall utility of risk or vulnerability maps is dependent on the scale at which factor base maps has been compiled. VINAS-LSP has been designed at regional scale; therefore attempts to extract site-specific information will be a major misuse of this tool.

The GSA applied in this work has allowed exploring the importance of factors and justifying their inclusion in the model structure. Additionally, the validation technique showed that the model adequately addressed the main aim of developing a territory-wide approach to groundwater vulnerability assessment.

Table 4

VINAS-LSP values and areal distribution of potential risks.

\begin{tabular}{lllr}
\hline Class (i) & Level of potential risk & VINAS-LSP value & Area (\%) \\
\hline 1 & Very low & $0.000-0.200$ & $54 \%$ \\
2 & Low & $0.201-0.400$ & $4 \%$ \\
3 & Medium & $0.401-0.600$ & $18 \%$ \\
4 & High & $0.601-0.800$ & $17 \%$ \\
5 & Very high & $0.801-1.000$ & $7 \%$ \\
\hline
\end{tabular}


This research has proved that it is possible to develop a robust model to identify territories with different degrees of risk to nitrate pollution. VINAS-LSP model was successfully tested at regional level. The resulting LSP map is a regional screening tool that can provide guidance on the potential risk of nitrate pollution, as well as highlight areas that require specific research and/or a decrease in the nitrogen load.

\section{Acknowledgments}

The authors thank the group of environmental experts involved in the eliciting of scores for VINAS-LSP factors. Boris Rebolledo is supported by Chilean Scholarship (Becas Chile) from de National Q2 Commission for Science Research and Technology (CONICYT, Chile).

\section{References}

Addiscott, T.M., Benjamin, N., 2004. Nitrate and human health. Soil Use Manag. 20, 98-104.

Aguaron, J., Moreno-Jiménez, J.M., 2003. The geometric consistency index: approximated thresholds. Eur. J. Oper. Res. 147, 137-145.

Aller, L., Lehr, J.H., Petty, R., Bennett, T., 1987. Drastic-a standardized system to evaluate groundwater pollution potential using hydrogeologic setting. J. Geol. Soc. India 29, 23-37.

Andreu, J., Betrán, J., Delgado, I., Espada, J.L., Gil, M., Gutiérrez, M., Iguácel, F., Isla, R., Muñoz, F., Orús, F., Pérez, M., Quílez, D., Sin, E., Yagüe, M.R., 2006. Fertilización nitrogenada Guía de actualización. Gob. Aragón - Dep. Agric. y Aliment.

Arauzo, M., Martínez-Bastida, J.J., 2015. Environmental factors affecting diffuse nitrate pollution in the major aquifers of central Spain: groundwater vulnerability vs. groundwater pollution. Environ. Earth Sci. 1-16.

Arauzo, M., Valladolid, M., 2013. Drainage and N-leaching in alluvial soils under agricultural land uses: implications for the implementation of the EU nitrates directive. Agric. Ecosyst. Environ. 179, 94-107.

Böhner, J., Blaschke, T., Montanarella, L., 2008. Continental-scale digital soil mapping using european soil Profile data: soil pH. SAGA - second. Out. Hambg. Beiträge zur Phys. Geogr. Landschaftsökologie 19, 113.

Chowdhury, S.H., Kehew, A.E., Passero, R.N., 2003. Correlation between nitrate contamination and ground water pollution potential. Groundwater 41, 735-745.

Civita, M., 1994. Le Carte Della Vulnerabilità Degli Acquiferi All'inquinamento. Teoria e pratica. Pitagora Ed. - Bol. 325

Civita, M., De Regibus, C., 1995. Sperimentazione di alcune metodologie per la valutazione della vulnerabilitadegli aquiferi. Q. Geol. Appl. Pitagora Bol. 3, 63-71.

Crosetto, M., Tarantola, S., Saltelli, A., 2000. Sensitivity and uncertainty analysis in spatial modelling based on GIS. Agric. Ecosyst. Environ. 81, 71-79.

Cuadrat, J.M., Saz, M.A., S.M., V.-S., 2007. Atlas Climático de Aragón - Gobierno de Aragón.

De Paz, J.M., Ramos, C., 2004. Simulation of nitrate leaching for different nitrogen fertilization rates in a region of Valencia (Spain) using a GIS-GLEAMS system. Agric. Ecosyst. Environ. 103, 59-73.

DGA, 2007. Atlas climático de Aragón. Departamento de medioambiente. Diputación Gobierno de Aragón (DGA).

DGA, 2012. Sistema básico de información climática de Aragón (SiClima). Departamento de Agricultura, Ganaderia y Medio Ambiente - Gobierno de Aragón, Apunt. Metod.

DGA, 2014. IDE ARAGON, Infraestructura de datos espaciales de Aragon [WWW Document]. URL. http://idearagon.aragon.es/.

Doerfliger, N., Jeannin, P.Y., Zwahlen, F., 1999. Water vulnerability assessment in karst environments: a new method of defining protection areas using a multiattribute approach and GIS tools (EPIK method). Environ. Geol. 39, 165-176.

Drobne, S., Lisec, A., 2009. Multi-attribute decision analysis in GIS: weighted linear combination and ordered weighted averaging. Nature 4, 28 .

Dujmovic, J., 1979. Partial absorption function. J. Univ. Belgr. EE Dept. Ser. Math. Phys. 659, 156-163.

Dujmović, J., 1996. A method for evaluation and selection of complex hardware and software systems. In: CMG 96 Proceedings.

Dujmović, J., De Tré, G., Dragićević, S., 2009. Comparison of multicriteria methods for land-use suitability assessment. In: Proceeding of the 13th IFSA World Congress and the 6th EUSFLAT Conference. Lisbon, Portugal, pp. 1404-1409.

Dujmović, J., Scheer, D., 2010. Logic aggregation of suitability maps, in: fuzzy Systems (FUZZ). In: 2010 IEEE International Conference on, pp. 1-8.

Dujmović, J., Tré, G. De, 2011. Multicriteria methods and logic aggregation in suitability maps. Int. J. Intell. Syst. 26, 971-1001.

Dujmović, J.J., De Tré, G., Van de Weghe, N., 2008. Suitability maps based on the LSP method. In: Modeling Decisions for Artificial Intelligence. Springer, pp. 15-25.

Dujmović, J.J., De Tré, G., Van de Weghe, N., 2010. LSP suitability maps. Soft Comput. $14,421-434$.

Dujmović, J.J., Nagashima, H., 2006. LSP method and its use for evaluation of Java IDEs. Int. J. Approx. Reason 41, 3-22.

Eastman, J.R., 1999. Multi-criteria evaluation and GIS. Geogr. Inf. Syst. 1, 493-502.

Escobar, M.T., Aguarón, J., Moreno-Jiménez, J.M., 2004. A note on AHP group consistency for the row geometric mean priorization procedure. Eur. J. Oper. Res. $153,318-322$.

European Commission, 2004. ESDB V2.0: “The European Soil Database Distribution v.2.0. EUROPEAN COMMISSION AND THE EUROPEAN SOIL BUREAU NETWORK" CD-ROM.

European Commission, 2013. REPORT from the COMMISSION to the COUNCIL and the EUROPEAN PARLIAMENT on the Implementation of Council Directive 91/ 676/EEC Concerning the Protection of Waters against Pollution Caused by Nitrates from Agricultural Sources (2008-2011). Brussels.

Foster, S., 1987. Fundamental concepts in aquifer vulnerability, pollution risk and protection strategy. In: Van Duijvenbooden, W., Van Waegeningh, H.G. (Eds.), Vulnerability Soil Groundw. To Pollut. Comm. Hydrol. Res.

Galve, J.P., Sánchez, J.A., Pérez, A., Pascual, G., Coloma, P., 2005. Vulnerability to farming contamination of the aragon aquifers: methodology, results and GIS tool. In: ENCORE SEMINAR 2005. “Integrated River-basin Management Seminar".

Hinsby, K., de Melo, M.T.C., Dahl, M., 2008. European case studies supporting the derivation of natural background levels and groundwater threshold values for the protection of dependent ecosystems and human health. Sci. Total Environ. $401,1-20$

Jones, R.J.A., Hiederer, R., Rusco, E., Loveland, P.J., Montanarella, L., 2003. The Map of Organic Carbon in Topsoils in Europe. Eur. Communities, Italy.

JRC, 2006. SIMLAB, Software for Uncertainty and Sensitivity Analysis, Version 2.2. Developed by the Joint Research Centre (JRC), ISPRA. Available online at: http:/ simlab.jrc.ec.europa.eu (acceded June 2013).

Karr, J.D., Showers, W.J., Gilliam, J.W., Andres, A.S., 2001. Tracing nitrate transport and environmental impact from intensive swine farming using delta nitrogen15. J. Environ. Qual. 30, 1163-1175.

Lasserre, F., Razack, M., Banton, O., 1999. A GIS-linked model for the assessment of nitrate contamination in groundwater. J. Hydrol. 224, 81-90.

Ledoux, E., Gomez, E., Monget, J.M., Viavattene, C., Viennot, P., Ducharne, A., Benoît, M., Mignolet, C., Schott, C., Mary, B., 2007. Agriculture and groundwater nitrate contamination in the Seine basin. The STICS-MODCOU modelling chain. Sci. Total Environ. 375, 33-47.

Lilburne, L., Tarantola, S., 2009. Sensitivity analysis of spatial models. Int. J. Geogr. Inf. Sci. 23, 151-168.

Masetti, M., Poli, S., Sterlacchini, S., 2007. The use of the weights-of-evidence modeling technique to estimate the vulnerability of groundwater to nitrate contamination. Nat. Resour. Res. 16, 109-119.

Padovani, L., Trevisan, M., 2002. I nitrati di origine agricola nelle acque sotterranee. In: Un indice parametrico per l'individuazione di aree vulnerabili. Pitagora editrice, Bologna.

Panno, S.V., Kelly, W.R., Martinsek, A.T., Hackley, K.C., 2006. Estimating background and threshold nitrate concentrations using probability graphs. Groundwater 44, 697-709.

Rebolledo, B., 2014. Vulnerabilidad del territorio a la contaminación de nitratos de origen agrario. Desarrollo y aplicación del modelo paramétrico IVNA LSP. Universidad de Zaragoza. Available online: http://zaguan.unizar.es/record/13860? $\ln =\mathrm{es}$

Ribeiro, L., 2000. IS: um novo indice de susceptibilidade de aquiferos á contaminaçao agrícola ([SI: a new index of aquifer susceptibility to agricultural pollution]).

Ryden, J.C., Whitchead, D.C., 1988. Some relationships between denitrification potential and fractions of organic carbon in air-dried and field-moist soils. Soil Biol. Biochem. 20, 737-741.

Saaty, T.L., 1980. The Analytic Hierarchy Process. McGraw-Hill, New York.

Saltelli, A., Chan, K., Scott, E.M., 2000. Sensitivity Analysis. Wiley, New York.

Srinivasan, R., Arnold, J.G., 1994. Integration of a basin-scale water quality model with GIS1. JAWRA J. Am. Water Resour. Assoc. 30, 453-462.

Van Stempvoort, D., Ewert, L., Wassenaar, L., 1993. Aquifer vulnerability index: a GIS-compatible method for groundwater vulnerability mapping. Can. Water Resour. J. 18, 25-37.

Weyer, P.J., Cerhan, J.R., Kross, B.C., Hallberg, G.R., Kantamneni, J., Breuer, G. Jones, M.P., Zheng, W., Lynch, C.F., 2001. Municipal drinking water nitrate level and cancer risk in older women: the Iowa Women's Health Study. Epidemiology 12, 327-338.

Worrall, F., Spencer, E., Burt, T.P., 2009. The effectiveness of nitrate vulnerable zones for limiting surface water nitrate concentrations. J. Hydrol. 370, 21-28. 